(2)

\title{
Excessively anterior placement of the fibular interfragmentary screw can result in a malreduced ankle syndesmosis - a technical report
}

This article was published in the following Dove Press journal:

Orthopedic Research and Reviews

I5 December 2009

Number of times this article has been viewed

S Mukhoapadhyay'

A R Guha'

R Thomas'

A M Perera'

P Mullaney ${ }^{2}$

'Orthopaedic Foot and Ankle Unit, ${ }^{2}$ Department of Radiology, University Hospital of Wales, Cardiff, UK
Correspondence: S Mukhopadhyay

Flat-4, 20 Heol-Hir, Cardiff,

CFI4 5AE, UK

Tel +447828 652404

Fax +44 2920744206

Email sudiptomohan@doctors.org.uk
Abstract: The detection of often missed, syndesmotic injury in ankle fractures is important to reduce unacceptable clinical outcomes including possible future ankle arthritis. A case is presented in which the malpositioning of an interfragmentary screw has caused malreduction of syndesmosis.

Keywords: syndesmotic injury, ankle fracture, arthritis

\section{Introduction}

As many as $20 \%$ of ankle fractures that require internal fixation have a syndesmotic injury. ${ }^{1,2}$ Nonetheless these injuries may often be missed even after open reduction and internal fixation. Untreated they result in unacceptable clinical outcomes including an increased risk of ankle arthritis. ${ }^{3}$ Therefore it is important to ensure that the joint is adequately reduced and fixed. ${ }^{4}$ Perception of clear space and tibiofibular overlap to exclude syndesmotic injury during surgery on image intensifier views can be difficult. ${ }^{5}$ Vigilance must be kept for a number of structures that can be trapped at the syndesmosis preventing reduction such as bone fragments ${ }^{6}$ or a trapped posterior tibial tendon. ${ }^{7}$ Inadequate fixation can also lead to unreduced syndesmosis. ${ }^{8}$ We present a case where following internal fixation of a malpositioned interfragmentary screw has caused malreduction of syndesmosis. No similar case report was found in the available published English literature.

\section{Case report}

A 54-year-old gentleman sustained a Weber B ankle fracture with intact medial structures following a twisting injury whilst on holiday out of our region. He had his initial treatment at the local hospital. This was achieved with a seven hole one-third tubular plate fixation of the lateral malleolus (Figure 1). An interfragmentary compression cortical screw was used across the oblique fracture in lag mode. Intraoperative dynamic screening of the syndesmosis was performed and the syndesmosis was felt to be stable. He was then discharged in a below-knee lightweight cast with a follow-up appointment arranged in our unit at two weeks. Radiographs revealed acceptable overall alignment, however, inadequate reduction of the syndesmosis was suspected.

On this basis, a computer tomography (CT) scan was performed which revealed an inadequate reduction of the syndesmosis. The interfragmentary screw head was noted to be low and anterior and protruding into the anterior part of the syndesmosis (Figure 2). submit your manuscript | www.dovepress.com

Dovepress 


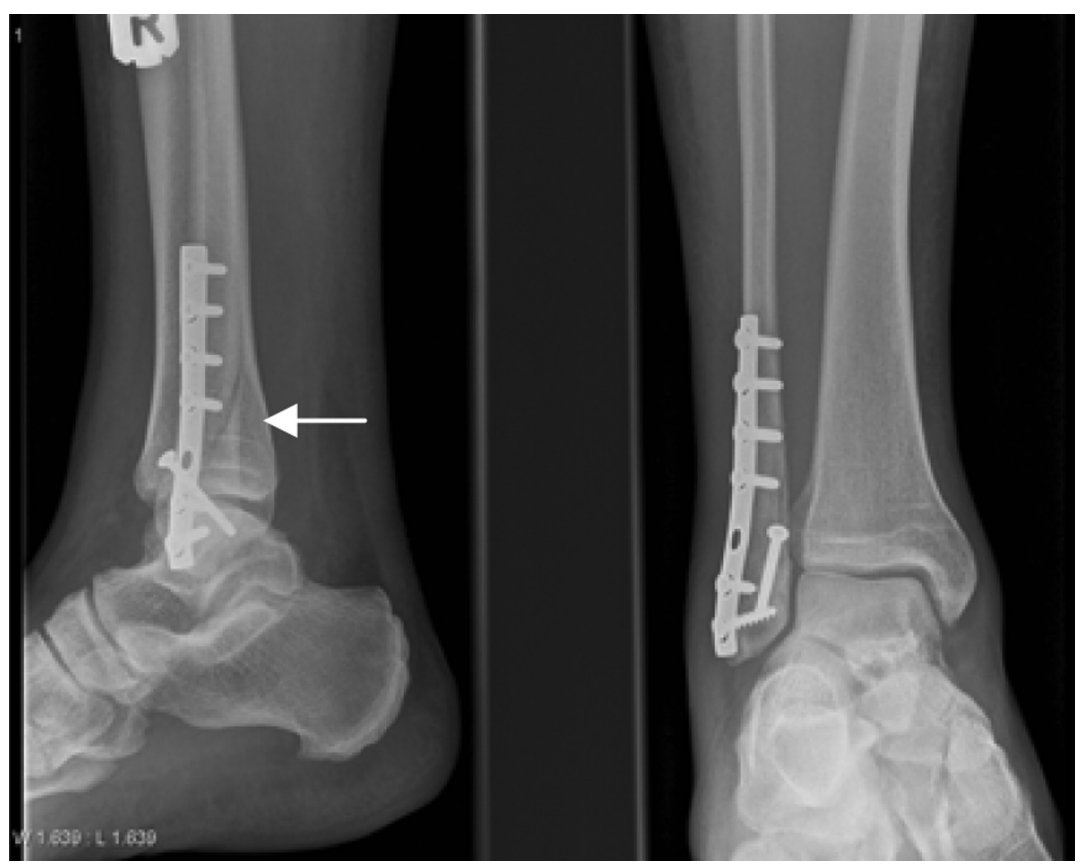

Figure I Postoperative radiographs of initial ankle fixation with interfragmentary screw in-situ (arrow-fracture line).
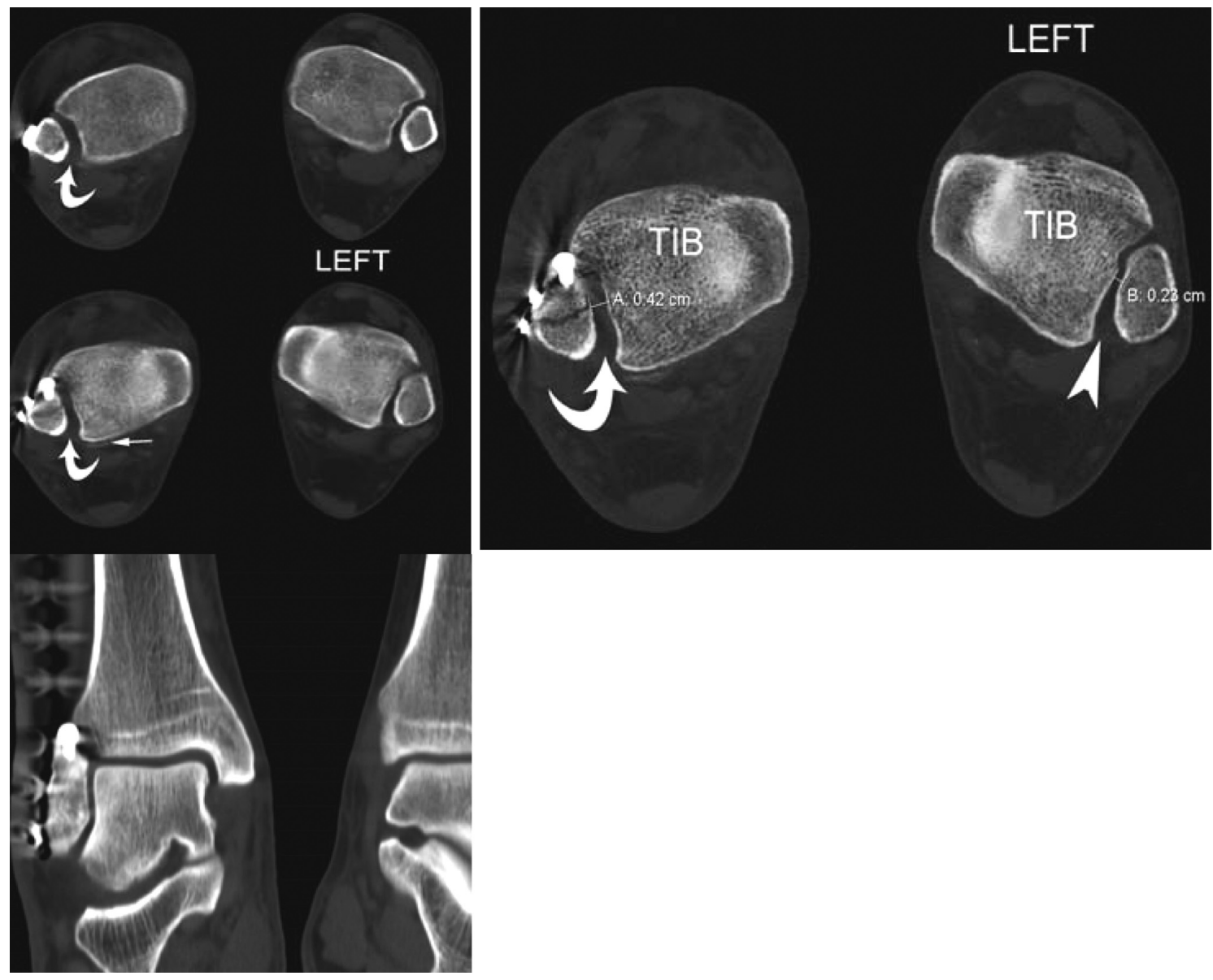

Figure 2 Axial and coronal computed tomography acquisitions demonstrating the interposing screw head causing malreduction (curved arrows: malreduced syndesmosis; arrowhead: normal syndesmosis). 
A

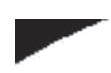

B

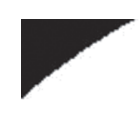

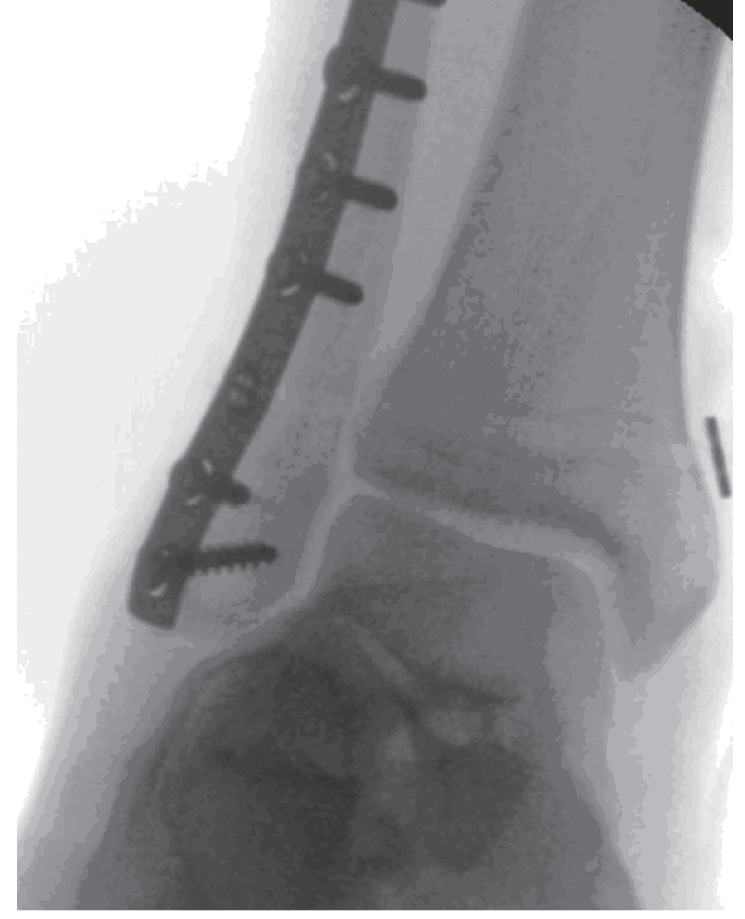

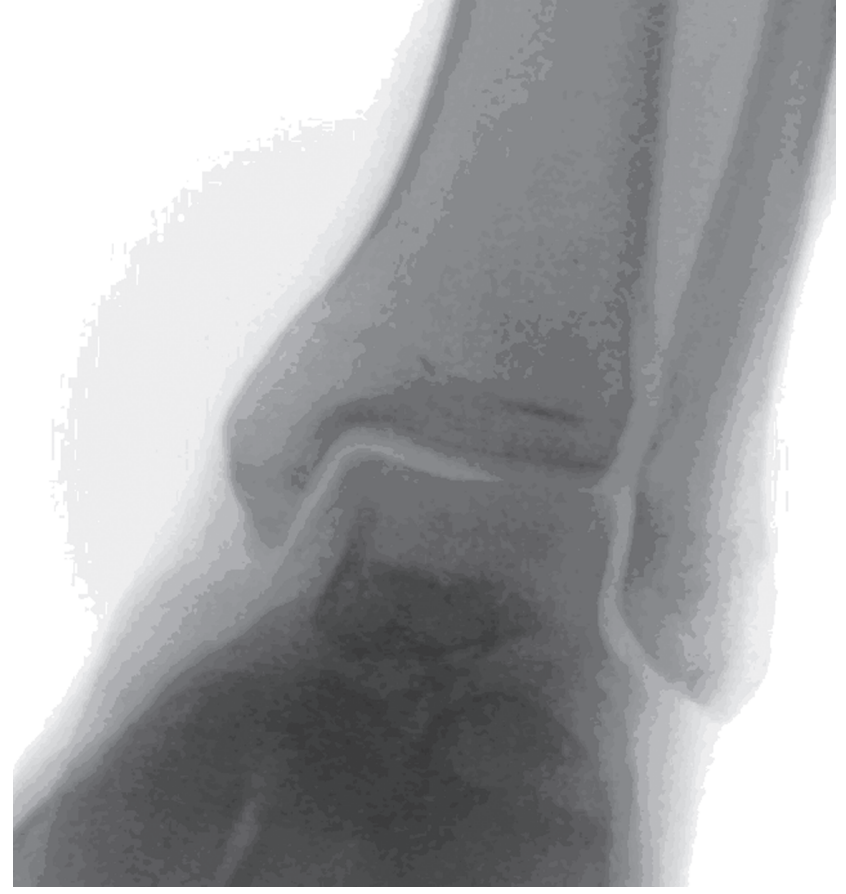

C

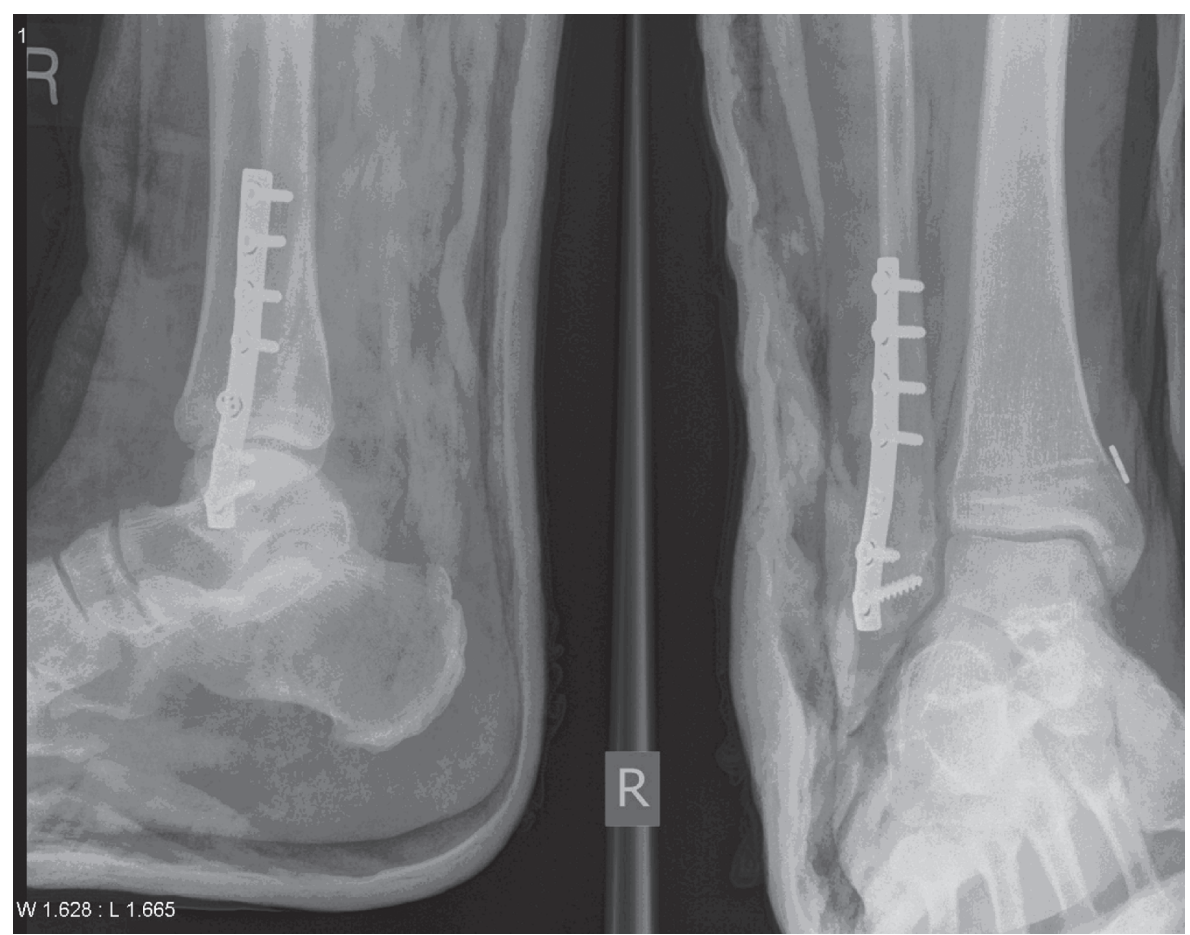

Figure 3 A) Intraoperative imaging of the injured right ankle showing adequate reduction of syndesmosis. B) Normal left ankle radiograph used as a template. C) Postoperative imaging of adequately reduced syndesmosis. 
The patient was re-operated on at this stage in order to reduce and stabilize the syndesmosis. Intraoperatively the contralateral ankle was imaged and used as template. Initially a closed reduction was attempted with aid of a reduction clamp but the joint failed to reduce. Therefore a small lateral incision was made in order to perform a debridement and reduction of the syndesmosis. However the interfragmentary screw head was felt to be sited within the joint interfering with accurate reduction. Following removal of the screw the joint was seen to close and was confirmed on imaging. A tightrope was used to stabilize the syndesmosis as referenced to the normal ankle (Figures 3a, 3b, and 3c).

\section{Discussion}

Abnormal loading through tibio-talar articulation leads to increased joint reaction force, predisposing the joint to arthritis. ${ }^{9,10}$ The consequences of an unreduced syndesmosis such as development of early ankle arthritis, stiffness, abnormal gait are well-documented. $3,11,12$

Gardner and colleagues ${ }^{8}$ performed a study of twenty-five patients with postoperative evaluation of syndesmosis reduction comparing the efficacy of plain radiograph and CT scan. In their series $24 \%$ of patients had malreduction using a difference of $2 \mathrm{~mm}$ between anterior and posterior measurements at the incisura fibularis. ${ }^{8}$ Despite the fact that such malreduction is yet to be correlated with clinical outcomes it is perceived that this should be avoided to prevent future problems.

Based on the available evidence the removal of the screw was indicated and immediately solved the malalignment. We used a tightrope method instead of a metallic screw to hold the reduction of the syndesmosis; this has been reported to provide a similar or better clinical result. ${ }^{13}$ Additionally the use of a tightrope is important to avoid over tightening of the syndesmosis and perhaps permit the normal kinematics of the fibula. ${ }^{14}$

\section{Conclusion}

Recent evidence suggests that accurate reduction of the syndesmosis $^{3}$ is crucial to achieve a good functional outcome. It is important to keep a high clinical suspicion in order to recognize malreduction of the syndesmosis, as in this case and appropriate measures to correct the malalignment should be undertaken to

Orthopedic Research and Reviews

\section{Publish your work in this journal}

Orthopedic Research and Reviews is an international, peer-reviewed, open access journal that focusing on the patho-physiology of the musculoskeletal system, trauma, surgery and other corrective interventions to restore mobility and function. Advances in new technologies, materials, techniques and pharmacological agents are particularly welcome. The journal welcomes

Submit your manuscript here: http://www.dovepress.com/orthopedic-research-and-reviews-journal prevent future complications. Furthermore in a low fracture, such as in this case, care must be taken to ensure that the interfragmentary screw does not interfere with the reduction of syndesmosis. The utility of CT scanning in this situation is well demonstrated in this case. Large scale studies to specifically identify correlation of syndesmotic reduction and clinical outcomes are required for further consolidation of this view.

\section{Disclosures}

The authors report no conflicts of interest in this work.

\section{References}

1. Kennedy JG, Johnson SM, Collins SL, et al. An evaluation of the Weber classification of ankle fractures. Injury. 1998;29:577-580.

2. Pettrone FA, Gail M, Pee D, Fitzpatrick T, Van Herpe LB. Quantitative criteria for prediction of the results after displaced fracture of the ankle. J Bone Joint Surg Am. 1983;65A:667-677.

3. Weening B, Bhandari M. Predictors of functional outcome following transsyndesmotic screw fixation of ankle fractures. J Orthop Trauma. 2005;19:102-108.

4. Fites B, Kunes J, Madaleno J, Silvestri P, Johnson DL. Latent syndesmosis injuries in athletes. Orthopedics. 2006;29(2):124-127.

5. Jenkinson RJ, Sanders DW, Macleod MD, Domonkos A, Lydestadt J. Intraoperative diagnosis of syndesmosis injuries in external rotation ankle fractures. J Orthop Trauma. 2005;19:604-609.

6. Lee BJ, Lee SR, Kim ST, Park WS, Kim TH, Park KH. Irreducible fracture-dislocation of the ankle caused by an entrapped medial malleolus at the syndesmosis. J Orthop Trauma. 2008;22(3):209-212.

7. Curry EE, O'Brien TS, Johnson JE. Fibular nonunion and equinovarus deformity secondary to posterior tibial tendon incarceration in the syndesmosis: a case report after a bimalleolar fracture-dislocation. Foot Ankle Int. 1999;20(8):527-531.

8. Gardner MJ, Demetrakopoulos D, Briggs SM, Helfet DL, Lorich DG. Malreduction of the tibiofibular syndemsosis in ankle fractures. Foot Ankle Int. 2006;27:788-792.

9. Ramsey PL, Hamilton W. Changes in tibiotalar area of contact caused by lateral talar shift. J Bone Joint Surg Am. 1976;58A:356-357.

10. Thordarson DB, Motamed S, Hedman T, Ebramzadeh E, Bakshian S. The effect of fibular malreduction on contact pressures in an ankle fracture malunion model. J Bone Joint Surg Am. 1997;79:1809-1815.

11. Chissel HR, Jones J. The influence of a diastasis screw on the outcome of Weber type-C ankle fractures. J Bone Joint Surg Br. 1995;77B:435-438.

12. Leeds HC, Ehrlich MG. Instability of the distal tibiofibular syndesmosis after bimalleolar and trimalleolar ankle fractures. J Bone Joint Surg Am. 1984;66-A:490-503.

13. Kaukonen JP, Lamberg T, Korkala O, Pajarinen J. Fixation of syndesmotic ruptures in 38 patients with a malleolar fracture: a randomized study comparing a metallic and a bioabsorbable screw. J Orthop Trauma. 2005;19:392-395.

14. Tornetta P 3rd, Spoo JE, Reynolds FA, Lee C. Overtightening of the ankle syndesmosis: is it really possible? J Bone Joint Surg Am. 2001;83A(4):489-492.

original research, clinical studies, reviews \& evaluations, expert opinion and commentary, case reports and extended reports. The manuscript management system is completely online and includes a very quick and fair peer-review system, which is all easy to use. Visit http://www.dovepress. com/testimonials.php to read real quotes from published authors.

\section{Dovepress}

